\title{
A General Approach to Sizing and Power Density Equations for Comparison of Electrical Machines
}

\author{
Surong Huang, Jian Luo, Student Member, IEEE, Franco Leonardi, Associate Member, IEEE, \\ and Thomas A. Lipo, Fellow, IEEE
}

\begin{abstract}
Whenever an electrical machine is meant to be fed by a power converter, the design should be approached as a system optimization, more than a simple machine sizing. A great variety of electrical machines is available to accomplish this goal, and the task of comparing the different options can be very difficult. A general purpose sizing equation, easily adjustable for every topology, that could take into account different waveforms and machine characteristics, would be a very desirable tool. In this paper, a general approach is presented to develop and to discuss such an equation. Sample applications of the sizing and power density equations are utilized to compare the induction machine and the doubly salient permanent magnet (DSPM) machine.
\end{abstract}

Index Terms-Ferrites, magnets, motors, power density, sizing equation.

\section{INTRODUCTION}

$\mathbf{I}$ $\mathrm{N}$ GENERAL, the comparison of different machine types is a very formidable task, since many variables exist for each machine and it is difficult to select those quantities which should be held constant and those that should be left free to vary. One traditional method of comparison is to use the $D_{g}^{2} L_{e}$ sizing equation, which compares the machine power on the basis of the airgap volume, where $D_{g}$ is the airgap diameter and $L_{e}$ the effective stack length.

For many years, researchers have been interested in considering, instead, the machine outer diameter $D_{o}$, because it is more directly related to the volume and, thus, to the cost and size of the machine. In 1987, Honsinger developed a $D_{o}^{2} L_{e}$ sizing equation for induction machines [1]. This method emphasized the importance of choosing the right electrical loading $A$ on the machine optimization. Unfortunately, the approach leads to good designs only for small pole numbers, since optimizing $D_{0}^{3} L_{e}$ is clearly not the same as optimizing $D_{o}^{3} L_{e}$.

The traditional sizing equation is based on the assumption that the excitation of the machine is provided by a sinusoidal

Paper IPCSD 97-61, presented at the 1996 Industry Applications Society Annual Meeting, San Diego, CA, October 6-10, and approved for publication in the IEEE TRANSACTIONS ON INDUSTRY APPLICATIONS by the Electric Machines Committee of the IEEE Industry Applications Society. Manuscript released for publication September 5, 1997.

S. Huang was with the Department of Electrical and Computer Engineering, University of Wisconsin, Madison, WI 53706-1691 USA. He is now with the College of Automation, Shanghai University, Shanghai, 200072 China (email: srhuang@yc.shu.edu.cn).

J. Luo and T. A. Lipo are with the Department of Electrical and Computer Engineering, University of Wisconsin, Madison, WI 53706-1691 USA (e-mail: luoj@cae.wisc.edu; lipo@engr.wisc.edu).

F. Leonardi was with the Department of Electrical and Computer Engineering, University of Wisconsin, Madison, WI 53706-1691 USA. He is now with McLeer Power Inc., Jackson, MI 49203 USA.

Publisher Item Identifier S 0093-9994(98)01326-7. voltage source, resulting in ac machines which produce a sinusoidal EMF. It was recognized in [2] and [3] that the emergence of power electronic converters has removed the need for such a concept as the basis for machine design. Beginning with the reluctance and brushless permanent magnet (PM) machine, a new phase of electrical machine design has been evolving, based on the principle that the best machine design is the one that simply produces the optimum match between the machine and the power electronic converter.

Given the great number of possible motor choices, it has become important to compare the power potential of machines with vastly different topologies and having a variety of different waveforms of back EMF and current. A systematic and easy-to-use method based on sizing equations is, therefore, very desirable to compare the capability of machines with different structures.

In order to eliminate the deficiencies of traditional sizing equations, this paper introduces special factors to account for the effect of nonsinusoidal current and back EMF waveforms. A particular effort is made to obtain a sizing equation which characterizes the output power $P_{R}$ as a function of the overall volume of the machine. Thus, machines can be compared based upon the total occupied volume, instead of the airgap volume. The application of this general purpose sizing equation should provide machine designers with an important tool in their quest for new high-power density machines and structures.

\section{Sizing Equations And Power Densities}

In general, if stator leakage inductance and resistance are neglected, the output power for any electrical machine can be expressed as

$$
\begin{aligned}
P_{R} & =\eta \frac{m}{T} \int_{0}^{T} e(t) i(t) d t \\
& =\eta m K_{p} E_{\mathrm{pk}} I_{\mathrm{pk}}
\end{aligned}
$$

where EMF $e(t)$ and $E_{\mathrm{pk}}$ are the phase airgap EMF and its peak value. The currents $i(t)$ and $I_{\mathrm{pk}}$ are the phase current and the peak phase current, $\eta$ is the machine efficiency, $m$ is the number of phases of the machine, and $T$ is the period of one cycle of the EMF. The quantity $K_{p}$ is termed the electrical power waveform factor and is defined as

$$
\begin{aligned}
K_{p} & =\frac{1}{T} \int_{0}^{T} \frac{e(t) \times i(t)}{E_{\mathrm{pk}} \times I_{\mathrm{pk}}} d t \\
& =\frac{1}{T} \int_{0}^{T} f_{e}(t) f_{i}(t) d t
\end{aligned}
$$


where $f_{e}(t)=e(t) / E_{\mathrm{pk}}$ and $f_{i}(t)=i(t) / I_{\mathrm{pk}}$ are the expressions for normalized EMF and current waveforms.

The peak value of EMF $E_{\mathrm{pk}}$ and the EMF itself $e(t)$ in (1) are given by

$$
E_{\mathrm{pk}}=K_{e} N_{t} B_{g} \frac{f}{p} D_{g} L_{e}
$$

and

$$
e(t)=\frac{d \lambda_{g}(t)}{d t}=K_{e} N_{t} B_{g} \frac{f}{p} D_{g} L_{e} f_{e}(t)
$$

where $\Lambda_{g}$ is the airgap flux linkage per phase, $N_{t}$ is the number of turns per phase, $f$ is the converter frequency, and $p$ is machine pole pairs. The constant $K_{e}$ is the EMF factor which incorporates the winding distribution factor $K_{w}$ and the ratio between the area spanned by the (salient) poles and the total airgap area.

In order to indicate the effect of the current waveform, the definition of a current waveform factor $K_{i}$ is also useful:

$$
K_{i}=\frac{I_{\mathrm{pk}}}{I_{\mathrm{rms}}}=\left(\frac{1}{T} \int_{0}^{T}\left(\frac{i(t)}{I_{\mathrm{pk}}}\right)^{2} d t\right)^{-1 / 2}
$$

where $I_{\mathrm{rms}}$ is the rms phase current which is related to the stator electrical loading $A_{s}$, wherein

$$
A_{s}=2 m_{1} N_{t} \frac{I_{\mathrm{rms}}}{\pi D_{g}}
$$

where $m_{1}$ is the number of phases of each stator (if there is more than one stator, each stator has the same $m_{1}$ ). The factor 2 is introduced here because $N_{t}$ is the number of turns per phase, instead of the number of conductors per phase.

In the general case, the total electrical loading $A$ should include both the stator electrical loading $A_{s}$ and rotor electrical loading $A_{r}$, so that

$$
A_{s}=A-A_{r}=\frac{A}{1+K_{\phi}}
$$

where $K_{\phi}=A_{r} / A_{s}$ is the ratio of electrical loading on rotor and stator. In a machine topology without a rotor winding, $K_{\phi}=0$.

Inserting (6) and (7) into (5),

$$
I_{\mathrm{pk}}=\frac{1}{1+K_{\phi}} K_{i} A \pi \frac{D_{i}}{2 m_{1} N_{t}} .
$$

Combining (1), (4), and (8), the following $D_{g}^{2} L_{e}$ sizing equation is obtained:

$$
P_{R}=\frac{1}{1+K_{\phi}} \frac{m}{m_{1}} \frac{\pi}{2} K_{e} K_{i} K_{p} \eta B_{g} A \frac{f}{p} D_{g}^{2} L_{e} .
$$

In most radial airgap flux machines, the aspect ratio coefficient

$$
K_{L}=\frac{L_{e}}{D_{g}}
$$

should be chosen based upon practical requirements of the application. Alternatively, in [4] and [5], an optimized range of the ratio of stack length versus pole pitch was given for conventional motors as a function of peak torque and temperature rise. From this data, through power regression, it is possible to obtain

$$
K_{L}=\frac{\pi}{2} p^{-(2 / 3)}
$$

However, this is clearly not the case for axial airgap flux machines, for which $K_{L}$ must be carefully derived [6].

Inserting (10) into (9), it is possible to obtain a $D_{g}^{3}$ sizing equation:

$$
P_{R}=\frac{1}{1+K_{\phi}} \frac{m}{m_{1}} \frac{\pi}{2} K_{e} K_{i} K_{p} K_{L} \eta B_{g} A \frac{f}{p} D_{g}^{3} .
$$

To realize the required $D_{o}^{3} L_{e}$ sizing equation, it is useful to define the ratio [1]

$$
\lambda_{o}=\frac{D_{g}}{D_{o}}=f\left(d_{s s}, d_{c s}, L_{p m}, D_{g}, p\right)
$$

where $d_{s s}$ is the depth of the stator slot, $d_{c s}$ is the depth of the stator core, and $L_{p m}$ is the length of the PM in the radial direction in the stator, if any. In general, the format of the function $f$ will depend on the specific machine type, and it is impossible to derive a general format valid for every machine. A procedure needs to be developed to determine $\lambda_{\circ}$ when studying a specific machine considering the effects of temperature rise, losses, and efficiency requirements. In practice, the depths $d_{s s}$ and $d_{c s}$ depend upon the stator electrical loading $A_{s}$, the current density $J_{s}$, the slot fill factor $K_{c u}$, and the flux density in the iron core. The length $L_{p m}$ depends on the airgap flux density and airgap length, and the airgap surface diameter $D_{g}$ is determined by (12).

The final general purpose sizing equation ultimately takes on the following form:

$$
P_{R}=\frac{1}{1+K_{\phi}} \frac{m}{m_{i}} \frac{\pi}{2} K_{e} K_{i} K_{p} \eta B_{g} A \frac{f}{p} \lambda_{o}^{2} D_{o}^{2} L_{e} .
$$

For convenience of design and for purposes of comparison, the corresponding $D_{o}^{3}$ sizing equation is found to be

$$
P_{R}=\frac{1}{1+K_{\phi}} \frac{m}{m_{1}} \frac{\pi}{2} K_{e} K_{i} K_{p} K_{L} \eta B_{g} A \frac{f}{p} \lambda_{o}^{3} D_{o}^{3} .
$$

Finally, the machine power density for the total volume can be defined as

$$
\xi=\frac{P_{R}}{\frac{\pi}{4} D_{o}^{2} L_{t}}
$$

where $L_{t}$ is the total length of the machine, including the stack length and the protrusion of the end winding from the iron stack in the axial direction.

By examining the back EMF and current waveform for a particular machine type, the factors $K_{i}$ and $K_{p}$ in the sizing equation can be determined. Several typical waveforms and their corresponding $K_{i}$ and $K_{p}$ are shown in Table I. 
TABLE I

TYPICAL PROTOTYPE WAVEFORMS

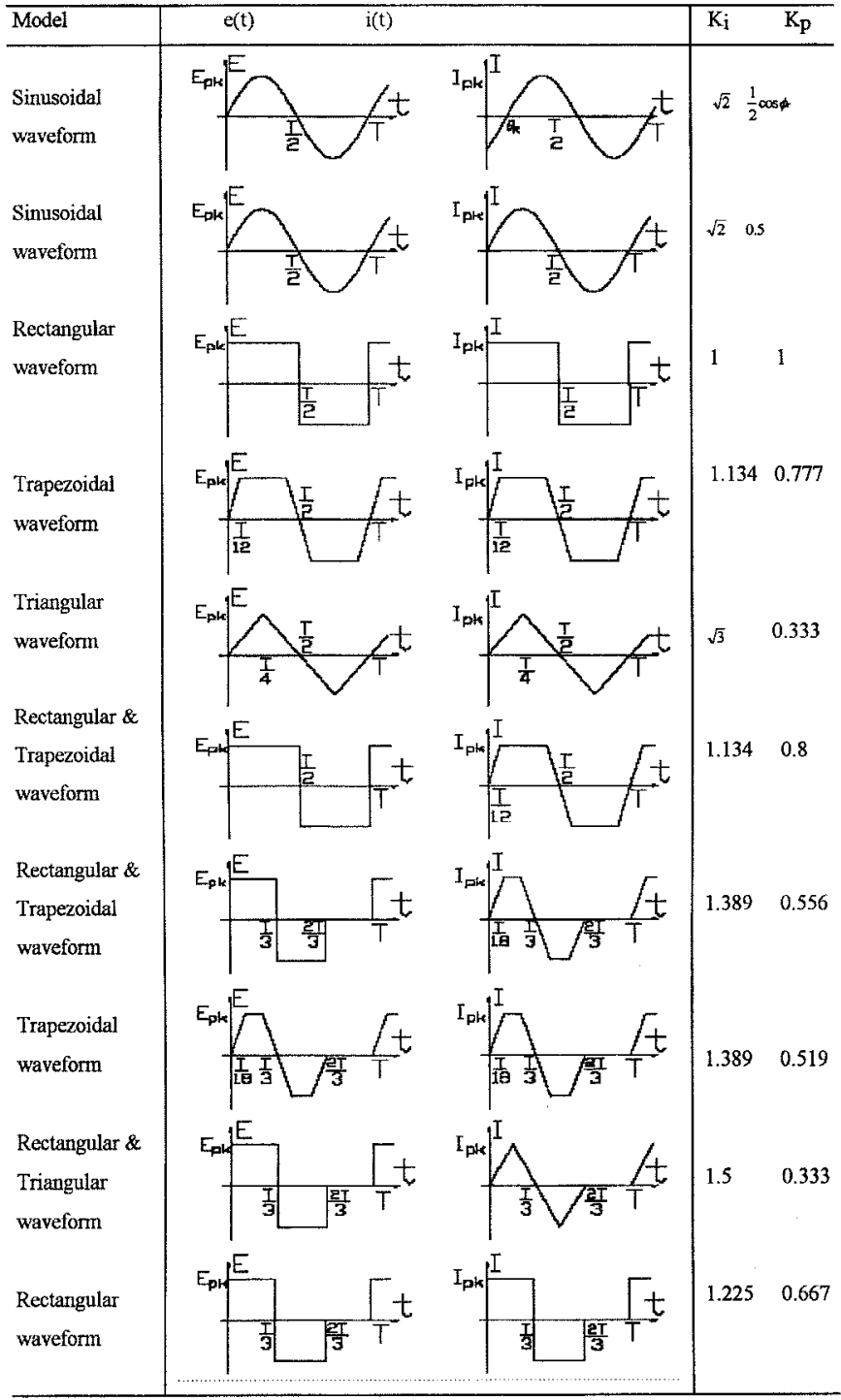

\section{Application of the Generalized Sizing EQUATION TO INDUCTION MACHINES}

Considering the first sinusoidal back EMF and current waveforms inherent in induction machines (Table I, row 1), it is clear that $K_{i} K_{p}=(\sqrt{2} / 2) \cos \phi_{r}$. For an induction machine, the factor $K_{e}=2 \pi K_{w}$. Then, from (14), the sizing equation of an induction machine is

$$
P_{R(I M)}=\frac{\sqrt{2} \pi^{2}}{2\left(1+K_{\phi}\right)} K_{w} \eta \cos \phi_{r} B_{g} A \frac{f}{p} \lambda_{o}^{2} D_{o}^{2} L_{e} .
$$
is

The corresponding power density of the induction machine

$$
\xi_{(I M)}=\frac{2 \sqrt{2} \pi^{2}}{\left(1+K_{\phi}\right)} K_{w} \eta \cos \phi_{r} B_{g} A \frac{f}{p} \lambda_{o}^{2} \frac{L_{g}}{L_{t}}
$$

where $\cos \phi_{r}$ is the power factor which is related to the rated power $P_{R(I M)}$, the pole pairs $p$ of the machine, and the converter frequency $f$. An estimate of $\cos \phi_{r}$ for the squirrel-
TABLE II

VARIATION OF K (WITH RATED POWER FACTOR $\cos \phi_{r}$

\begin{tabular}{l|l|l|l|l|l|l|c}
\hline $\cos \phi_{r}$ & 0.65 & 0.7 & 0.75 & 0.8 & 0.85 & 0.9 & 0.95 \\
\hline$K_{\phi}$ & 0.74 & 0.77 & 0.82 & 0.86 & 0.9 & 0.95 & 0.985 \\
\hline
\end{tabular}

TABLE III

ReCOMMENDED VALUES OF $B_{q}$ AND $B_{t s}$ FOR DifFERENT Source FREQUENCIES $f$

\begin{tabular}{l|l|l|l|l|l|l}
\hline$f(\mathrm{~Hz})$ & 40 & 50 & 60 & 80 & 200 & 400 \\
\hline$B_{t s}(\mathrm{~T})$ & 1.68 & 1.56 & 1.48 & 1.35 & 1.00 & 0.80 \\
\hline$B_{g}(\mathrm{~T})$ & 1.25 & 1.10 & 0.95 & 0.8 & 0.48 & 0.38 \\
\hline
\end{tabular}

cage motor is

$$
\cos \phi_{r}=1.07 P_{R}^{0.015} p^{-0.08} f^{-0.07} \text {. }
$$

The above equation was verified through the NEMA-B squirrel-cage motor data, which were discussed in [5].

In an induction machine, $K_{\phi}$ is related to the rated power factor $\cos \phi_{r}$. In [7], a table (see Table II) was given to express the relationship between $K_{\phi}$ and $\cos \phi_{r}$.

Through power regression, an estimated equation for $K_{\phi}$ can be established as

$$
K_{\phi}=1.06 P_{R}^{0.0116} p^{-0.062} f^{-0.054} \text {. }
$$

Choice of a proper airgap flux density $B_{g}$ and stator tooth flux density $B_{t s}$ is another important issue. Reference [5] offers a discussion of the relationship between $B_{t s}$ and converter frequency $f$. From this source, the stator tooth flux density $B_{t s}$ can be estimated reasonably by

$$
B_{t s}=5.47 f^{-0.32} \text {. }
$$

In addition, Levi [8] has derived an optimal value for $B_{g}$ expressed as

$$
B_{g}=0.5 K_{f e} B_{t s} K_{h 1}
$$

where $K_{f e}$ is the stator lamination factor accounting for the air space between laminations. Note that symbol $B_{g}$ here represents the fundamental component of airgap flux density, hence, $K_{h 1}$ is a factor to convert the airgap flux density waveform to its fundamental component; if the machine is not saturated and the airgap flux density has a sinusoidal waveform, then $K_{h 1}$ equals 1 . If the machine is highly saturated and the airgap flux density has a nearly rectangular waveform, the factor $K_{h 1}$ will have a maximum value of $\pi / 2$.

Table III shows some typical flux densities suggested for several converter frequencies.

In induction machines having an outer stator topology, the machine outer surface diameter $D_{o}$ is given by

$$
D_{o}=D_{g}+2\left(d_{c s}+d_{s s}\right)
$$

where $d_{s s}$ is the depth of stator slot, $d_{c s}$ is the depth of stator core given by

$$
d_{c s}=\frac{B_{g} \alpha_{p}}{4 p K_{f e} B_{c s}} \pi D_{g}
$$

where $B_{c s}$ is the flux density in the stator core, and $\alpha_{p}$ is the ratio of average airgap flux density to peak airgap flux density. 
The depth of the stator slot $d_{s s}$ is

$$
d_{s s}=\frac{2 A_{s}}{K_{d s} J_{s} K_{c u}}=\frac{2 A}{\left(1+K_{\phi}\right) K_{d s} J_{s} K_{c u}}
$$

where $K_{d s}$ is the trapezoidal slot factor which is used to convert a trapezoidal slot to an equivalent rectangular slot for computational purpose.

Inserting (23)-(25) into the definition of $\lambda_{o}[(13)]$ finally yields an equation for $\lambda_{0}$ for the case of an induction machine having an outer stator radial airgap flux topology

$$
\begin{aligned}
\lambda_{o} & =\frac{D_{g}}{D_{o}}=\frac{D_{g}}{D_{g}+2 d_{c s}+2 d_{s s}} \\
& =\left(1+\frac{\pi B_{g} \alpha_{p}}{2 p K_{f e} B_{c s}}+2 K_{s s}\right)^{-1}
\end{aligned}
$$

where $K_{s s}=d_{s s} / D_{g}$.

Through a computational study, it is now possible to design a series of machines with different power ratings, pole pairs, and converter frequencies and to examine efficiency for various designs. To assure the reliability of such data, the results obtained from such a study were compared with published data on NEMA-B series motors, the efficiency of which can be approximated by

$$
\eta=0.7 P_{R}^{0.03} p^{-0.025} f^{-0.01}
$$

Of course, the efficiency of any electrical machine can be obtained by accurately calculating the losses in the machine. However, a detailed calculation of losses would unnecessarily complicate the sizing equation concept, which is intended to be a reasonably simple estimate of the machine size.

\section{Application of the Generalized Sizing EQuation to Doubly Salient Permanent Magnet (DSPM) Machines}

The DSPM machine concept has been presented in [2] and [9]. For the DSPM topology (Figs. 1 and 2), it can be determined that $K_{e}=\pi$. Because there is no rotor winding, $K_{\phi}=0$. The trapezoidal waveforms in Table I (row 8), are good approximations of the actual waveform and gives $K_{i} K_{p}=0.721$. From (14), the following DSPM machines sizing equation is obtained:

$$
P_{R(\mathrm{DSPM})}=0.361 \pi^{2} \eta B_{g} A \frac{f}{p} \lambda_{o}^{2} D_{o}^{2} L_{e}
$$

where the power density of the DSPM machine is

$$
\xi_{(\mathrm{DSPM})}=1.444 \pi \eta B_{g} A \frac{f}{p} \lambda_{o}^{2} \frac{L_{e}}{L_{t}} .
$$

Due to the structure of the DSPM machine, the waveforms of the flux in different portions of the stator and rotor have different characteristics. In the stator teeth and the stator inner core, the flux has a unipolar pulsating waveform. In the stator outer core, a nearly constant flux exists. Only in the rotor teeth and core is there truly an ac flux.

It is very important to choose reasonable values of the flux density for the different portions of the DSPM machine. An optimization of such values will increase the power density of the machine and decrease the iron loss. After an in-depth computational study and optimization, it was found that the

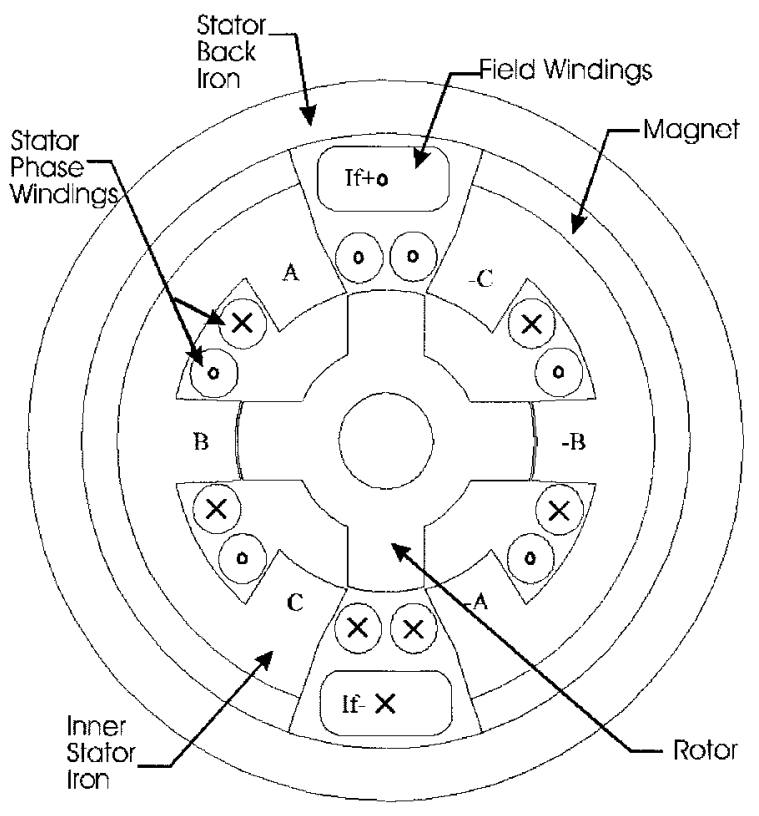

Fig. 1. DSPM4/6 machine with stator pole number $p_{s}=6$, rotor pole number $p_{r}=4$, and pole pairs $p=4$.

flux density in stator teeth should be designed according to the following expression:

$$
B_{t s}=\left\{\begin{array}{lr}
2, & f \leq 20 \mathrm{~Hz} \\
5.47 f^{-0.32}, & 20 \mathrm{~Hz}<f<60 \mathrm{~Hz} . \\
1.48-\left(1.48-5.47 f^{-0.32}\right) / 1.4, & f \geq 60 \mathrm{~Hz}
\end{array}\right.
$$

Generally, the airgap flux density $B_{g}$ and the rotor tooth flux density $B_{t r}$ are specified to match $B_{t s}$. Based on the same numerical analysis, the flux density in the stator inner core should be

$$
B_{c s 1}=1.48-\left(1.48-5.47 f^{-0.32}\right)
$$

and the flux density in the stator outer core

$$
B_{c s 2}=1.4 \sim 1.8
$$

where the value of $B_{c s 2}$ is chosen according to field weakening requirements.

The flux density in the rotor core is

$$
B_{c r}=4.38 f^{-0.32} \text {. }
$$

In any PM machine, the airgap flux density $B_{g}$ can also be expressed as

$$
B_{g}=K_{\text {focus }} B_{u}
$$

where $B_{u}$ is the attainable flux density on the surface of the PM's. The quantity $K_{\text {focus }}$ is the flux-focusing factor, which is related to the structure of the PM machine and takes the form

$$
K_{\text {focus }}=\frac{A_{p m}}{A_{p}} K_{d}
$$

where $A_{p m}$ is the surface area of PM's, $A_{p}$ is the area of the gap surface physically crossed by the flux, and $K_{d}$ is the flux leakage factor of the PM machines obtained through a finite-element study or through design experience. 


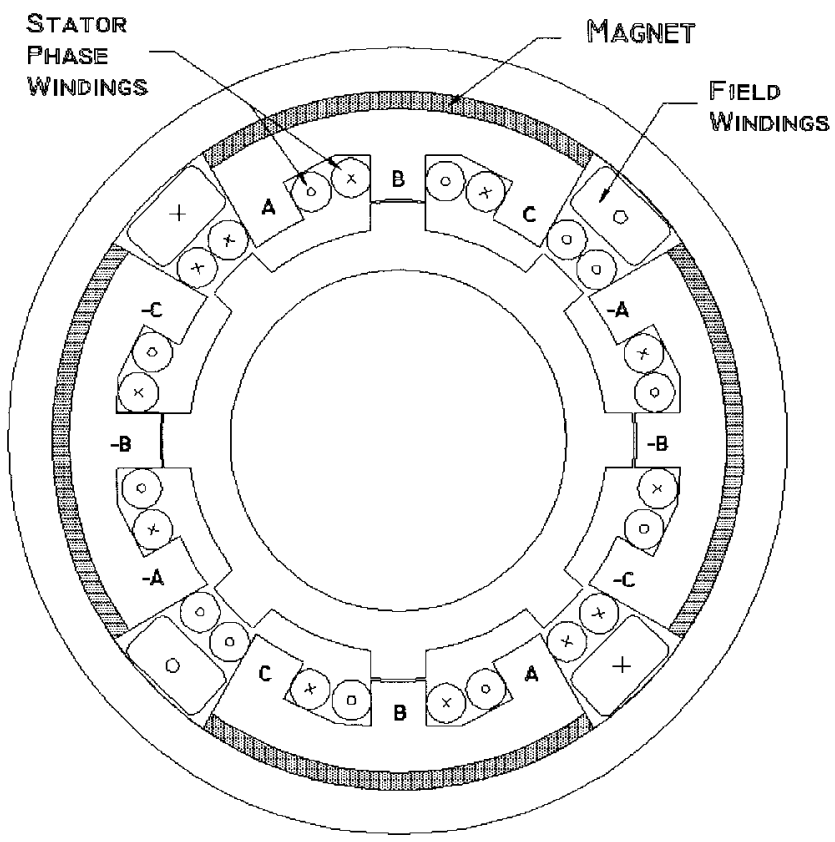

Fig. 2. DSPM8/12 machine with stator pole number $p_{s}=12$, rotor pole number $p_{r}=8$, and pole pairs $p=8$.

The optimal values of the aspect ratio coefficient $K_{L}$ was given considering power density and efficiency and is, for DSPM4/6 machines, $K_{L}=1.40 \sim 1.55$ and, for DSPM8/12 machines, $K_{L}=0.65 \sim 0.75$.

In DSPM machines, the outer surface diameter $D_{o}$ can be expressed as

$$
D_{o}=D_{g}+2\left(d_{c s 1}+d_{c s 2}+d_{s s}+L_{p m}\right)
$$

where $d_{c s 1}$ is the depth of the stator inner core given by

$$
d_{c s 1}=\frac{2 \alpha_{s}}{2+\alpha_{s}} \frac{B_{t s}}{B_{c s 1}} \frac{\pi D_{g}}{p_{s}}
$$

and where $\alpha_{s}$ is the ratio of stator teeth portion to the stator pole pitch portion. For the structure shown in Figs. 1 and 2, where $\alpha_{s}=0.5$, the quantity $d_{c s 2}$ is the depth of stator outer core given by

$$
d_{c s 2}=\frac{\alpha_{s}}{2} \frac{B_{t s}}{B_{c s 2}} \frac{\pi D_{g}}{p_{s}} .
$$

The length of the PM is expressed as

$$
L_{p m}=\frac{1.2 \mu_{r} B_{u}}{0.95 B_{r}-\frac{B_{u}}{K_{d}}} K_{\text {focus }} g
$$

where $B_{r}$ is the residual flux density of the PM material and $g$ is the length of airgap. Reference [8] offers the following equation for estimating the airgap:

$$
g=4.710^{-3} p^{-0.5} D_{g} .
$$

The depth of stator slot in the case of the DSMP is

$$
d_{s s}=\frac{2 A}{K_{d s} J_{s} K_{c u}} .
$$

Referring to the definition of $\lambda_{o}[(13)]$ and the structure of the DSPM machine (Figs. 1 and 2), the inner-to-outer-surface-

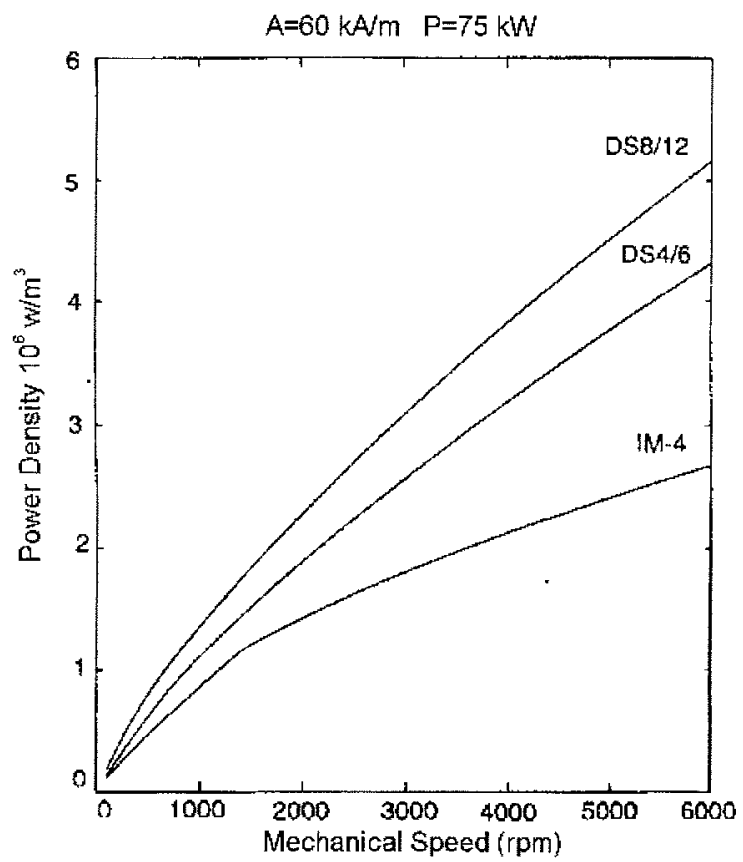

Fig. 3. Power densities of four-pole IM and DSPM machines.

diameter ratio becomes

$$
\begin{aligned}
\lambda_{o}= & \frac{D_{g}}{D_{o}}=\frac{D_{g}}{D_{g}+2 d_{c s 1}+2 d_{c s 2}+2 L_{P M}+2 d_{s s}} \\
= & \left(1+0.8 \frac{B_{t s}}{B_{c s 1}} \frac{\pi}{p_{s}}+0.5 \frac{B_{t s}}{B_{c s 2}} \frac{\pi}{p_{s}}+1.128\right. \\
& \left.\cdot 10^{-2} \frac{\mu_{r} B_{u}}{0.95 B_{r}-\frac{B_{u}}{K_{d}}} K_{\text {focus }} p^{-0.5}+2 K_{s s}\right)^{-1} .
\end{aligned}
$$

Since DSPM machines are not widely used, the available data are insufficient to provide general expressions for the efficiency of such machines. A theoretical or a numerical approach is, therefore, necessary to give an estimate of their efficiency. The method adopted in this paper was to produce a number of computer generated designs, estimate the efficiency, and then utilize a power regression algorithm to obtain the efficiency equation. The estimated efficiency of the DSPM machines thus obtained is given by

$$
\eta=0.92 P_{R}^{0.01} p^{-0.015} f^{-0.01} .
$$

Again, calculating the total losses of DSPM machines directly will yield a more accurate estimate of efficiency.

\section{COMPARISON BETWEEN INDUCTION AND DSPM MACHINES}

It is now possible to calculate the power densities of induction machines and DSPM machines through the use of the sizing and power density equations. Fig. 3 shows the comparison of power densities among the four-pole induction machine (IM-4), the four-rotor-pole/six-stator-pole DSPM ma- 
chine (DS4/6) and the eight-rotor-pole/12-stator-pole DSPM machine (DS8/12). The curves of Fig. 3 represent an interpolation between a great number of computer-generated machine designs. Each speed corresponds to a different machine which has its rated value at that point. The $x$ axis should not be regarded as a speed range, but rather as rated speed. An effort was made to optimize the power density of each machine, achieving comparable, but not identical, efficiency and steadystate temperature. The comparison is based on the same current density, total current loading, and rated power. The induction machine (IM) motor data have been checked with available commercial products and appear to represent well the vast world of induction motors.

This study promises a power density improvement of nearly a factor of two for high-speed DSPM's over the induction motor. A slight efficiency penalty is expected at high speed because of DSPM8/12 has a relatively high pole number and, consequently, high flux frequency.

While corroborating test results cannot be included in this paper, some details on DSPM motor testing can be found in the literature [10]. More data are being collected and will soon be available.

\section{CONCLUSION}

In this paper, the following results have been obtained.

1) A general purpose sizing and power density equation was developed in terms of the main machine dimensions $D_{o}^{2} L_{e}$ instead of airgap dimensions $D_{g}^{2} L_{e}$. This new approach permits a comparison of the capability of different machine topologies based upon the overall occupied volume.

2) Sample applications of the general purpose sizing and power density equation have been developed for both DSPM machines and IM's.

3) A powerful comparison tool for electrical machines has been presented, and common limitations of previous approaches have been eliminated.

4) A fair comparison between IM's and DSPM machines was attempted. The DSPM structure appeared to be capable of substantially higher power density than the equivalent induction machine.

\section{REFERENCES}

[1] V. B. Honsinger, "Sizing equations for electrical machinery," IEEE Trans. Energy Conversion, vol. EC-2, pp. 116-121, Mar. 1987.

[2] T. A. Lipo and Y. Li, "CFMs-A new family of electrical machines," in Proc. IPEC'95, Yokohama, Japan, Apr. 3-7, 1995, pp. 1-8.

[3] T. A. Lipo and F. X. Wang, "Design and performance of converter optimized AC machines," IEEE Trans. Ind. Applicat., vol. IA-20, pp. 834-844, July/Aug. 1984.

[4] W. Schuisky, Induktionsmaschimen. Vienna, Austia: Springer-Verlag, 1957.

[5] T. A. Lipo, Introduction to AC Machine Design, Wisconsin Power Electronics Research Center, University of Wisconsin, Madison, WI, 1996.

[6] S. Huang, J. Luo, F. Leonardi, and T. A. Lipo, "A comparison of power density for axial flux machines based on the general purpose sizing equation," presented at the 1997 IEEE Power Engineering Society Summer Meeting, Berlin, Germany, July 20-24, 1997.

[7] S. Q. Chen, "Electrical machine design," Xian Jiaotong University, 1982, (in Chinese)
[8] E. Levi, Polyphase Motors-A Direct Approach to Their Design. New York: Wiley, 1984

[9] Y. Li, F. Leonardi, and T. A. Lipo, "A novel doubly salient permanent magnet generator capable of field weakening," presented at the Conference on Design to Manufacture in Modern Industry (DMMI), Lake Bled, Slovenia, May 29-30, 1995

[10] F. Leonardi, T. Matsuo, Y. Li, T. A. Lipo, and P. McCleer, "Design considerations and test results for a doubly salient PM motor with flux control," presented at the IEEE-IAS Annu. Meeting, San Diego, CA, Oct. 6-12, 1996.

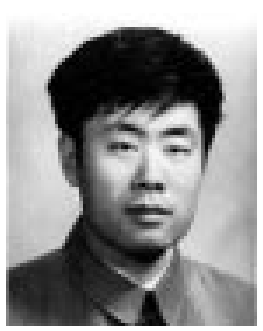

Surong Huang was born in Shanghai, China. He received the B.S. and M.S. degrees in electrical engineering from Shanghai University, Shanghai, China.

From 1995 to 1996, he was a Visiting Faculty Member at the University of Wisconsin, Madison. $\mathrm{He}$ is currently an Associate Professor, College of Automation, Shanghai University. His research interests are motor and drive design, power electronics, and power systems.

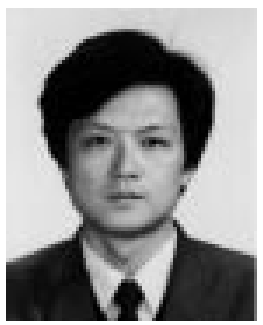

Jian Luo (S'96) was born in Chengdu, China. He received the B.S. degree from Tsinghua University, Beijing, China, in 1984 and the M.S. degree from the First Academy of Aerospace Industry, Beijing, China, in 1987, both in electrical engineering. He is currently working toward the Ph.D. degree at the University of Wisconsin, Madison.

Prior to entering the Ph.D. program, he was an Electrical Engineer with the Beijing Institute of Control Devices, Beijing, China. His areas of interest include optimized electrical machine and drive design, modeling, and simulation.

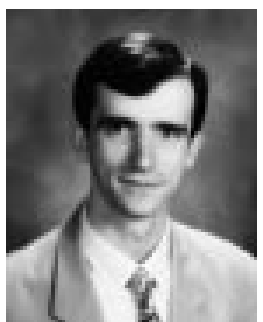

Franco Leonardi (S'93-A'95) received the Degree and the Doctorate degree in electrical engineering from the Universitá degli Studi di Padova, Padova, Italy, in 1991 and 1995, respectively.

From 1994 to early 1996, he was at the University of Wisconsin, Madison, where he was involved in research on synchronous reluctance and doubly salient permanent magnet motors. In 1996, he joined McCleer Power Inc., Jackson, MI, where he is currently engaged in the development of DSPM technology for traction applications and other re-

search projects.

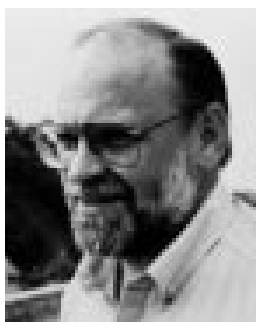

Thomas A. Lipo (M'64-SM'71-F'87) is a native of Milwaukee, WI. He received the Ph.D. degree from the University of Wisconsin, Madison, in 1968.

From 1969 to 1979, he was an Electrical Engineer in the Power Electronics Laboratory, Corporate Research and Development, General Electric Company, Schenectady, NY. He became Professor of Electrical Engineering at Purdue University, West Lafayette, IN, in 1979. In 1981, he joined the University of Wisconsin, Madison, where he is presently the W. W. Grainger Professor for Power Electronics and Electrical Machines.

Dr. Lipo has received the Outstanding Achievement Award from the IEEE Industry Applications Society, the William E. Newell Award of the IEEE Power Electronics Society, and the 1995 Nicola Tesla IEEE Field Award from the IEEE Power Engineering Society for his work. Over the past 30 years, he has served the IEEE in numerous capacities, including President of the Industry Applications Society. 